\title{
O PROCEDIMENTO DE NOTIFICAÇÃO COMPULSÓRIA NOS ESTABELECIMENTOS DE ENSINO NA NOVA POLÍTICA NACIONAL DE PREVENÇÃO DA AUTOMUTILAÇÃO E DO SUICÍDIO
}

\section{THE PROCEDURE FOR COMPULSORY NOTIFICATION IN \\ TEACHING ESTABLISHMENTS IN THE NEW NATIONAL POLICY TO PREVENT AUTOMUTILATION AND SUICIDE}

\section{FERNANDO NABÃO LOPES FERREIRA}

Mestre em Ciências Jurídicas com ênfase em Direitos da Personalidade do Centro Universitário de Maringá - UNICESUMAR. Endereço para acessar este CV: http://lattes.cnpq.br/4741661056991858.

\section{IVAN DIAS DA MOTTA}

Professor Permanente do Programa de Mestrado em Ciências Jurídicas pelo Centro Universitário de Maringá - Unicesumar. Possui graduação em Direito pela Universidade Estadual de Maringá (1996), mestrando em Direito das Relações Sociais pela Pontifícia Universidade Católica de São Paulo (1998) e doutorado em Direito das Relações Sociais pela Pontifícia Universidade Católica de São Paulo (2000), Pósdoutorado em Direito Educacional pela Pontifícia Universidade Católica de São Paulo (2001). Atualmente é professor permanente do Programa de Mestrado em Direito do Centro Universitário de Maringá, integrando a linha de pesquisa "A Tutela Constitucional e Privada dos Direitos da Personalidade nas Relações Privadas". Possui atuação profissional na área da advocacia e consultoria em Direito Educacional. Endereço para acessar este CV: http://lattes.cnpq.br/1508111127815799. ORCID: https://orcid.org/0000-0002-75156187. E-mail: ivan.iddm@gmail.com. Telefone: (44) 99883-0041 


\section{RESUMO}

O presente artigo tem como objetivo inicial abordar a violência como uma questão de saúde pública, na medida em que a violência ameaça as condições de vida, trabalho, as relações interpessoais, tratando-se de uma complexa reflexão sobre a violência e seus variados fatores condicionantes. No Estatuto da Criança e do Adolescente, o destaque à saúde está presente no artigo $7^{\circ}$, dispondo que "a criança e o adolescente têm direito a proteção à vida e à saúde, mediante a efetivação de políticas sociais públicas que permitam o nascimento e o desenvolvimento sadio e harmonioso, em condições dignas de existência". Apesar da classificação da violência como um problema de saúde pública, a proposta deste trabalho, e a problemática a ser levantada, é questionar como os estabelecimentos de ensino podem contribuir para a prevenção e combate da violência autoprovocada. Com o advento da Lei 13.819/19, que institui a Política Nacional de Prevenção da Automutilação e do Suicídio, o legislador prevê, em seu artigo $6^{\circ}$, inciso II e parágrafo $5^{\circ}$, que os casos suspeitos ou confirmados de violência autoprovocada são de notificação compulsória pelos estabelecimentos de ensino públicos e privados ao Conselho Tutelar, bem como, orienta os estabelecimentos de ensino a informar e treinar os profissionais que trabalham em seu recinto quanto aos procedimentos de notificação estabelecidos em Lei. Em última análise, o trabalho demonstrará como as políticas e programas implementadas pelos Ministérios da Saúde e Educação já desempenham esse trabalho no atual cenário brasileiro.

PALAVRAS-CHAVE: Violência Autoprovocada; Lei $n^{\circ}$ 13.819/2019; Políticas Públicas.

\section{ABSTRACT}

This article aims to address violence as a public health issue, as violence threatens living conditions, work, interpersonal relationships, and is a complex reflection on violence and its various conditioning factors. In the Statute of Children and Adolescents, the highlight on health is present in article 7, stating that "children and adolescents have the right to protection of life and health through the implementation 
of public social policies that allow birth and development. healthy and harmonious, in conditions worthy of existence ". Despite the classification of violence as a public health problem, the purpose of this paper, and the issue to be raised, is to question how schools can contribute to the prevention and combat of self-inflicted violence. With the advent of Law 13.819 / 19, which establishes the National Policy for the Prevention of Self-Harm and Suicide, the legislator provides, in article 6, item II and paragraph 5, that suspected or confirmed cases of self-harm are compulsory notification by the public and private schools to the Guardianship Council, as well as directing the schools to inform and train the professionals who work in its precincts regarding the notification procedures established by Law. The policies and programs implemented by the Ministries of Health and Education already perform this work in the current Brazilian scenario.

KEYWORDS: Self-inflicted Violence; Law no. 13.819 / 2019; Public Policy.

\section{INTRODUÇÃO}

A violência tem sido, e cada vez mais, motivo de preocupação no mundo e, também, no Brasil. A repercussão que a violência toma quando noticiado em veículos de comunicação expressa a gravidade do problema e a dificuldade em que o estado brasileiro se encontra quanto ao enfrentamento deste problema.

Atento a essa "adversidade", o legislador pátrio atribuiu direitos e deveres sobre a manutenção da segurança pública. No artigo 144 da Constituição Federal de 1988, tratou a segurança pública como dever do Estado, direito e responsabilidade de todos, sendo exercida para a preservação da ordem pública e da incolumidade das pessoas e do patrimônio.

Apesar de tratar-se de um problema de segurança pública, a violência também passou a ser vista como um problema de saúde pública, pois ameaça a vida, as condições de trabalho, as relações interpessoais, a qualidade de vida, ou seja, integra o mundo da saúde pública, tratando-se de uma complexa reflexão sobre a violência e seus fatores condicionantes. 
Assim como a preocupação com o combate da violência, o constituinte tratou sobre a garantia da saúde em seu texto, quando no artigo $6^{\circ}$ classificou a segurança pública e a saúde como direitos sociais, logo, direitos que demandam do Estado a necessária implementação de políticas nesse sentido e a efetivar a promoção, a proteção e a recuperação da saúde, nos moldes do artigo 196 da Constituição.

No Estatuto da Criança e do Adolescente, por sua vez, o destaque à saúde está presente no artigo $7^{\circ}$, quando versa que "a criança e o adolescente têm direito a proteção à vida e à saúde, mediante a efetivação de políticas sociais públicas que permitam o nascimento e o desenvolvimento sadio e harmonioso, em condições dignas de existência".

Visando garantir a proteção da saúde da criança e do adolescente, bem como efetivar políticas sociais públicas, em 26 de abril de 2019 foi sancionada a Lei 13.819/19, que institui a Política Nacional de Prevenção da Automutilação e do Suicídio. Com o advento da Lei 13.819/19, o legislador prevê, em seu artigo $6^{\circ}$, inciso II e parágrafo $5^{\circ}$, que os casos suspeitos ou confirmados de violência autoprovocada são de notificação compulsória pelos estabelecimentos de ensino públicos e privados ao Conselho Tutelar, bem como, estabelece que os estabelecimentos de ensino deverão informar e treinar os profissionais que trabalham em seu recinto quanto aos procedimentos de notificação estabelecidos em Lei.

Quanto à forma de prevenção, combate e estudo da violência autoprovocada, a nova Lei propõe, como um "meio", o procedimento de notificação compulsória na ocorrência do suicídio ou da automutilação. Ao se notificar a prática da violência autoprovocada, o Estado terá condições de aprofundar medidas relacionadas às condicionantes dessa modalidade de violência. A proposta é, portanto, legitimar o aspecto procedimental da construção do conhecimento e informação sobre o tema.

O processo de notificação, até então, era regulamentado apenas pelo Ministério da Saúde, porém, com a nova Lei, os estabelecimentos de ensino públicos e privados também deverão contribuir para o processo da construção de informações sobre a ocorrência dessa modalidade de violência, e é sobre essa nova demanda das instituições de ensino que a presente pesquisa se delineará.

Em última análise, serão demonstradas como as políticas implementadas pelos Ministérios da Saúde e Educação já desempenham o trabalho de efetivação da 
prevenção da violência autoprovocada por meio de políticas e programas, como, por exemplo, a Política Nacional de Saúde Mental, os trabalhos dos Centros de Valorização da Vida - CVV, a ação do "Setembro Amarelo" e, sob o viés educacional, o Programa Saúde na Escola - PSE.

\section{VIOLÊNCIA E SAÚDE PÚBLICA: A INTERDISCIPLINARIDADE DO TEMA.}

A violência não é uma, é múltipla. De origem latina, o vocábulo vem da palavra vis, que quer dizer força e se refere às noções de constrangimento e de uso da superioridade física sobre o outro. No seu sentido material o termo parece neutro, mas quem analisa os eventos violentos descobre que eles se referem a conflitos de autoridade, a lutas pelo poder e a vontade de domínio, de posse e de aniquilamento do outro ou de seus bens. Suas manifestações são aprovadas ou desaprovadas, lícitas ou ilícitas segundo normas sociais mantidas por usos e costumes naturalizados ou por aparatos legais da sociedade. Mutante, a violência designa, pois, de acordo com épocas, locais e circunstâncias, realidades muito diferentes. Há violências toleradas e há violências condenadas (MINAYO, 2005, p.12).

Para a Organização Mundial de Saúde - OMS (KRUG; et al., 2002, p.4), a violência é definida como sendo o uso intencional da força física ou do poder, real ou em ameaça, contra si próprio, contra outra pessoa, ou contra um grupo ou uma comunidade, que resulte ou tenha grande possibilidade de resultar em lesão, morte, dano psicológico, deficiência de desenvolvimento ou privação.

$\mathrm{Na}$ concepção de Minayo, Souza (1998, p.514) e Sposito (2012, p.3) a violência consiste em ações humanas de indivíduos, grupos, classes, nações que ocasionam a morte de outros seres humanos ou que afetam sua integridade física, moral, mental ou espiritual. É todo ato que implica na ruptura de um nexo social pelo uso da força. Nega-se, assim, a possibilidade da relação social que se instala pela comunicação, pelo uso da palavra, pelo diálogo e pelo conflito.

Sob o viés filosófico, Hannah Arendt (1970, p.28-29) entende que a violência distingue-se por seu caráter instrumental. Do ponto de vista fenomenológico, está ela próxima do vigor, uma vez que os instrumentos da violência, como todos os demais, 
são concebidos e usados para o propósito da multiplicação do vigor natural até que, nó último estágio de desenvolvimento, possam substituí-lo. O vigor designa inequivocamente alguma coisa no singular, uma entidade individual, trata-se de uma qualidade inerente a um objeto ou pessoa e que pertence ao seu caráter, a qual pode manifestar-se em relação a outras coisas ou pessoas, mas que é essencialmente independente deles.

Para Hannah Arendt (1970, p.38-40):

[...] o ódio pode certamente ser irracional e patológico, da mesma maneira que o podem ser todas as demais paixões humanas, e [...], criar condições que desumanizam o homem, tais como os campos de concentração, a tortura, a fome, porém, isto não significa que se tornem semelhantes aos animais; e nestas condições, não é o ódio ou a violência, mas a sua ausência conspícua que constitui o mais claro sinal de desumanização. O ódio não é de forma alguma uma reação automática à miséria e ao sofrimento como tais; ninguém reage com o sentimento de ódio a uma doença incurável ou a um terremoto ou a condições sociais que parecem imutáveis. Somente onde houver razão para suspeitar que as condições poderiam ser mudadas e não o são é que surgirá o ódio. Somente onde o nosso senso de justiça for ofendido é que reagiremos com ódio, e essa reação não refletirá de maneira alguma um dano pessoal, [...]. A violência é um recurso enormemente tentador quando se enfrenta acontecimentos ou condições ultrajantes, em razão de sua proximidade e rapidez. Agir com deliberada rapidez vai contra a essência do ódio e da violência, porém, isso não os torna irracionais. Muito pelo contrário, tanto na vida pública como privada há situações onde a própria rapidez de uma ação violenta seja talvez o único remédio adequado. $A$ questão não é que uma tal ação nos permite dar vazão aos nossos impulsos reprimidos, o que pode ser feito com a mesma eficácia se esmurrarmos a mesa ou batermos a porta. A questão é que em certas circunstâncias a violência, atuando sem argumentos ou discussões e sem atentar para as consequências, é a única maneira de se equilibrar a balança da justiça de maneira certa.

Segundo Éric Weil (PERINE, 2002, p.108-126) é a linguagem, ou a razão, que faz aparecer a violência. $O$ homem, ser agente e falante, é o único a revelar a violência, porque é o único a buscar e a criar um sentido para a sua vida e para o seu mundo, num mundo organizado e compreensível por referência à sua vida. Os animais podem ser violentos como os leões ou organizados como as formigas, mas só são violentos ou organizados aos olhos do homem, eles não se opõem nem se organizam em vista de criar alguma coisa. Só o homem conhece e designa a violência, o absurdo, o sem sentido. Para a fera, atirar-se sobre a sua presa não é insensato nem violento, assim como não é insensato nem violento não poder viver fora do formigueiro. $O$ 
homem é o único ser, pelo menos no estágio atual do conhecimento, que pode captar o insensato e dizer não ao insensato.

Indo de encontro a esta ideia, pode-se considerar que o homem só é violento porque é capaz de interpretar e compreender, porque é capaz de estabelecer uma relação com outro homem como homem (num universo do sentido, numa relação de reconhecimento e interpretação pela qual e objeto e simples natureza), e ele pode se tornar violento ou não violento apenas no universo do sentido que é o humano. Por isso, pode-se afirmar que a violência é constitutiva do mundo humano (PILATTI, 2016, p.28-29). A violência sempre está participando da "experiência humana". Seu impacto pode ser visto de várias formas, em diversas partes do mundo (KRUG, et al.,2002, p.3) e suas causas podem ser as mais diversas existentes.

Marilene Ristum (2001, p.75-78) lista como causas da violência os fatores sócio econômicos como a pobreza, a fome e a criminalidade; os institucionais, como a ausência de prevenção e repressão no sistema escolar, políticas habitacionais, de saúde e transporte público; fatores culturais, demografia urbana, meios de comunicação, a globalização e a sua consequente supressão de fronteiras.

Os problemas estudados por Jessé Souza (2009, p.95;15), Pierre Bourdieu (1989, p.10-11), Minayo e Souza (1999, p.12-13), e que mais afligem o Brasil são, do ponto de vista macroestrutural, as extremas desigualdades, a violência nos ambientes de trabalho e o desemprego, a exclusão social e a exclusão moral, a corrupção e a impunidade, problemas que se arrastam historicamente e, nesta etapa do desenvolvimento, têm grande peso sobre a dinâmica da violência. A violência é reflexo da reprodução da desigualdade e da exclusão social. Assim, o estigma e o preconceito social de toda espécie é percebido como experiência individualizada, ainda que socialmente compartilhada. A "violência simbólica", aquele tipo de violência que não "aparece" como violência, que torna possível a naturalização de uma desigualdade social abissal como a brasileira.

Sob o ponto de vista conjuntural, o aumento da violência se deve ao grande crescimento do crime organizado, nos grandes centros urbanos, sobretudo em torno do narcotráfico (o que repercute em outras formas de delinquência como assaltos a bancos, roubos de carros, de cargas, sequestros e outras formas de violência geral e difusa); do contrabando de armas de fogo; aumento da delinquência juvenil e dos 
crimes contra as pessoas e o patrimônio, favorecidos pelo clima de desemprego, impunidade e ausência de um projeto social que integre o conjunto dos estratos sociais (MINAYO; SOUZA, 1999, p.12-13).

Do ponto de vista cultural, interpessoal e privado, as elevadas taxas de violência contra a criança e o adolescente, contra a mulher, contra os idosos, a violência contra homossexuais e a discriminação racial. Quanto ao institucional, Raimundo Faoro (2001, p.201-202), Minayo e Souza (1999, p.12-13), entendem que a arraigada violência, corrupção, a morosidade da justiça, assim como incontáveis formas de discriminação e maus-tratos que ocorrem nos diferentes setores do Estado e na sua relação com a população, também influem na violência.

Em sua origem e manifestações, que a violência é um fenômeno sociohistórico e acompanha toda a experiência da humanidade. Portanto, ela não é, em si, uma questão de saúde pública. Transforma-se em problema para a área, porém, porque afeta a saúde individual e coletiva e exige, para sua prevenção e tratamento, formulação de políticas específicas e organização de práticas e de serviços peculiares ao setor (MINAYO, 2005, p.10).

Trata-se de um problema da sociedade, que desde a modernidade o tem tratado no âmbito da justiça, da segurança pública, e também como objeto de movimentos sociais. No entanto, dois fortes motivos tornam o assunto preocupação da área da saúde. O primeiro, porque, dentro do conceito ampliado de saúde, tudo o que significa agravo e ameaça à vida, às condições de trabalho, às relações interpessoais, e à qualidade da existência, faz parte do universo da saúde pública. Em segundo lugar, a violência, num sentido mais restrito, afeta a saúde e frequentemente produz a morte (MINAYO; SOUZA, 1999, p.11).

O estudo da saúde pública trata-se de um problema interdisciplinar com referenciais científicos. Ela se fundamenta em uma análise interdisciplinar, como no campo da medicina, epidemiologia, sociologia, psicologia, criminologia, educação e economia. A saúde pública é, acima de tudo, caracterizada por sua ênfase na prevenção, em vez de simplesmente aceitar ou reagir à violência, seu ponto de partida é a forte conviç̧ão de que tanto o comportamento violento quanto suas consequências podem ser evitados (KRUG, 2002, p.3). 
Por definição, a saúde pública não se refere a pacientes individuais. Seu foco está em lidar com doenças, condições e problemas que afetam a saúde, e seu objetivo é oferecer o máximo de benefícios para o maior número de pessoas. Isso não significa que a saúde pública ignore a assistência às pessoas enquanto indivíduos. Ao contrário, ela está preocupada em evitar os problemas de saúde e expandir uma melhor assistência e segurança para populações inteiras (KRUG, 2002, p.3).

Desde o início da década de 1980, o campo de saúde pública tem dado uma contribuição cada vez mais importante no que se refere à violência. Muitos profissionais, pesquisadores e sistemas de saúde pública tomaram para si as tarefas de entender as raízes da violência e evitar que ela ocorra(KRUG, 2002, p.3).

A Organização Pan-Americana de Saúde (OPAS - 1995 - 1993) declara que a violência, pelo número de vítimas e a magnitude de sequelas emocionais que produz, adquiriu um caráter endêmico e se converteu num problema de saúde pública em vários países. O setor de saúde constitui a encruzilhada para onde confluem todos os corolários da violência, pela pressão que exercem suas vítimas sobre os serviços de urgência, de atenção especializada, de reabilitação física, psicológica e de assistência social (MINAYO; SOUZA, 1997, p.520-528).

A Organização Mundial de Saúde (OMS) define a saúde como "um estado de completo bem-estar físico, mental e social e não somente ausência de afeções e enfermidades". A saúde passou, então, a ser mais um valor da comunidade que do indivíduo. É um direito fundamental da pessoa humana, que deve ser assegurado sem distinção de raça, de religião, ideologia política ou condição socioeconômica. A saúde é, portanto, um valor coletivo, um bem de todos, devendo cada um gozá-la individualmente, sem prejuízo de outrem e, solidariamente, com todos (OMS, 2016).

A necessidade de higiene mental é universal, é para todos. Para os efeitos da vida econômica e as reclamações da vida social, a noção de saúde mental é a de respostas psíquicas ajustadas, de boa adaptação, de relações humanas satisfatórias na família, no trabalho e na comunidade (OMS, 2016)

No contexto da saúde mental, para a Organização Mundial da Saúde (KRUG, 2002, p.6), a violência auto infligida é subdividida em comportamento auto abuso e suicida. $\mathrm{O}$ auto abuso inclui atos como a automutilação e o suicídio inclui pensamentos suicidas, tentativas de suicídio, também chamados de parassuicídio ou autolesão 
deliberada em alguns países, e suicídios completados. O comportamento auto lesivo é um problema de saúde pública que têm aumentado entre os adolescentes e no interior das escolas (ROSA, 2011, p.135-136), sendo os mais afetados pelo suicídio os jovens com idades 15 a 29 anos (THESOLIM, et al., 2016).

A violência auto infligida é a automutilação. Trata-se da destruição direta e deliberada de partes do corpo sem a intenção suicida consciente. Dividida em três categorias (KRUG, et al., 2002, p.183).

1) Automutilação grave: inclusive cegar-se e auto amputar-se dedos, mãos, braços, membros, pés ou genitália;

2) Automutilação estereotipada: tal como bater a cabeça, morder-se, bater no próprio braço, cortar os olhos ou a garganta, ou arrancar o cabelo;

3) Automutilação superficial a moderada: como cortar-se, arranhar-se ou queimar a pele, enfiar agulhas na pele ou arrancar os cabelos compulsivamente;

As formas mais frequentes de automutilação são os cortes superficiais, queimaduras, arranhões, mordidas, bater partes do corpo contra parede ou objetos e cutucar ferimento com consequente aumento destes ferimentos e sangramento (GIUSTI, 2013, p.5).

A automutilação é definida como qualquer comportamento intencional envolvendo agressão direta ao próprio corpo sem intenção consciente de suicídio e não socialmente aceita dentro de sua própria cultura e nem para exibição. A automutilação costuma ser repetitiva, podendo ocorrer mais de 50 atos independentes num mesmo indivíduo, mas as lesões são geralmente superficiais e sem repercussões sistêmicas. A automutilação pode ser pensada por algumas horas, minutos ou menos antes de executar cada incidente, dependendo da situação e oportunidade daquele que o pratique (GIUSTI, 2013, p.5).

Como fatores determinantes e condicionantes, a dificuldade em trabalhar o afeto, pode causar fragilidade emocional pela qual os adolescentes frequentemente passam nessa fase da vida, acrescido com a ausência de aptidão para suportar emoções dolorosas e habilidade de solucionar problemas, recorrendo à automutilação quando estão com problemas ou dificuldades, como angustias, crises de ansiedade, tristeza, raiva, sentimento de fracasso, depressão, episódios de despersonalização, baixa autoestima, perfeccionismo. Pode ser também um meio de autopunição e/ou de 
proporcionar uma sensação de controle interno, na tentativa de ser aceito pelo grupo e/ou ser parecido com alguém (GARRETO, 2015, p.13).

A automutilação é empregada como forma de lidar com fortes emoções e a adolescência é justamente o período em que os indivíduos começam a identificar melhor suas emoções e a vivê-las com maior intensidade, período de desenvolvimento da cognição social. Porém, nessa fase, as estruturas cerebrais relacionadas ao cérebro social, que são aquelas que auxiliam na expressão verbal de suas emoções, ainda estão em desenvolvimento. Assim, a adolescência acaba sendo o período de maior sensibilidade às emoções com menor capacidade de expressão e enfrentamento destas, colocando então os adolescentes em situação de maior vulnerabilidade para experimentar comportamentos como a automutilação (ou o uso de drogas) como forma de enfrentar estas emoções (GARRETO, 2015, p.16-17).

O comportamento suicida, por sua vez, vai desde simplesmente pensar em acabar com a vida até o desenvolvimento de um plano para cometer o suicídio e conseguir os meios de realizá-lo, ou seja, tentando se matar até finalmente realizar o ato (suicídio completado) (KRUG, et al., 2002, p.183).

Sob o viés da sociologia, Émile Durkheim (2000, p.14) define suicídio todo o caso de morte que resulte direta ou indiretamente de um ato positivo ou negativo, praticado pela própria vítima, sabedora de que devia produzir esse resultado. A tentativa é o ato assim definido, mas interrompido antes que dele resulte a morte.

Considerando que o suicídio é um ato da pessoa e que só a ela atinge, tudo indica que deva depender exclusivamente de fatores individuais e que sua explicação, por conseguinte, caiba tão somente à psicologia (DURKHEIM, 2000, p.16-17).

Se em lugar de se ver no suicídio apenas eventos particulares, isolados uns dos outros e que exijam, cada um deles, exame em separado, considera-se o conjunto dos suicídios cometidos em dada sociedade durante um dado espaço de tempo, verificar-se-á que o total assim obtido não é a simples soma de unidades independentes, um todo de coleção, mas que constitui por si mesmo um fato que é novo e sui generis, com unidade e individualidade, e, pois com sua natureza própria, e que, além disso, essa natureza é eminentemente social (DURKHEIM, 2000, p.17).

Para a Associação Brasileira de Psiquiatria - ABP (2014, p.9), o suicídio pode ser definido como um ato deliberado executado pelo próprio indivíduo, cuja intenção 
seja a morte, de forma consciente e intencional, mesmo que ambivalente, usando um meio que ele acredita ser letal. Também fazem parte do que habitualmente chama-se de comportamento suicida: os pensamentos, os planos e a tentativa de suicídio.

O suicídio está relacionado à angústia, ao próprio desejo do indivíduo e a fatores psíquicos relacionados. Sendo assim, um indivíduo só seria capaz de tirar a própria vida caso abdicasse à autopreservação. Além disso, a maior expressão de pulsão de morte seria a agressividade, e quando esta não está direcionada ao meio, pode voltar-se para si próprio e resultar em um suicídio (THESOLIM, et al., 2016, p.140).

Tanto a Organização Mundial da Saúde (KRUG, 2002, p.189) quanto a Associação Brasileira de Psiquiatria (2014, p.10), o suicídio é um fenômeno presente ao longo de toda a história da humanidade, em todas as culturas. É um comportamento com determinantes multifatoriais e resultado de uma complexa interação de fatores psicológicos e biológicos, inclusive genéticos, culturais, socioambientais, fatores demográficos, como idade e sexo. Dessa forma, deve ser considerado como o desfecho de uma série de fatores que se acumulam na história do indivíduo, não podendo ser considerado de forma causal e simplista apenas a determinados acontecimentos pontuais da vida do sujeito. É a consequência final de um processo.

O caso que tomou maior repercussão, e exemplo de violência autoprovocada foi o jogo virtual intitulado "Baleia Azul". ${ }^{1}$ Esse jogo é praticado em comunidades fechadas de redes sociais e instiga os participantes, em maioria adolescentes, a cumprir 50 tarefas, sendo a última delas o suicídio (CALDAS, 2017) A crescente interconexão, potenciada por processos de aproximação espacial e temporal, acarretou novos desafios para a segurança dos estados e dos indivíduos. As ameaças e os riscos encontram-se, cada vez menos, limitados pelas fronteiras nacionais, criando uma rede de crescentes interdependências, que acrescentam complexidade à governação da segurança global. Derivado o processo de globalização surgiram

\footnotetext{
${ }^{1}$ Sabe-se que esses desafios, conhecidos como "jogo da Baleia Azul", tiveram origem em 2015 nas redes sociais da Rússia e se espalharam pela Europa nos últimos dois anos. Na Rússia, as mortes de alguns adolescentes foram relacionadas ao jogo - embora não haja confirmação sobre esses relatos. (ORSI, 2017).
} 
inúmeras incertezas, que se concretizam em riscos variados para as sociedades (ESTEVENS, 2016)

De fato, com a evolução tecnológica, houve uma massificação de informações criando uma sensação de aproximação de tudo e de todos e consequentemente uma forte influência sobre o indivíduo. As informações vêm e vão de forma muita rápida de várias áreas e setores do mundo inteiro, fazendo, por muitas vezes, com que o indivíduo entre em uma crise de identidade (MOTTA; FERREIRA, 2017, p.9).

Um dos efeitos da globalização é a despersonalização. Stuart Hall (1992, p.9) fundamenta que há dificuldade de até mesmo se definir uma personalidade atualmente. Explica que as identidades modernas estão entrando em colapso e o indivíduo está se fragmentando, para Marx e Engels (1997, p.32) e Zygmunt Bauman (2007, p.84) as relações se volatilizam, se tornam liquidas. A perda de "um sentido de si" estável é chamada, algumas vezes, de deslocamento ou desconcentração do sujeito, explica o autor. Desconcentração dos indivíduos tanto de seu lugar no mundo social e cultural quanto de si mesmo. Constitui uma "crise de identidade" para o indivíduo.

O sentimento de identidade pode fazer uma importante contribuição à força $e$ ao calor de nossas relações com os outros, tais como vizinhos, membros da mesma comunidade, concidadãos ou adeptos da mesma religião. Nosso foco em identidades específicas pode enriquecer nossos laços e levar-nos a fazer muitas coisas para cada um, e pode ajudar a levar-nos além de nossa vida egoísta. Tal compreensão é importante, mas tem de ser complementada pelo reconhecimento mais extenso de que um sentimento de identidade pode excluir resolutamente muitas pessoas, mesmo enquanto generosamente inclui outras (2015, p.22).

Além disso, há um desfazimento dos laços do amor, proteção, solidariedade e confiança, vínculos que definiam a esfera privada da família, e também o espaço público. A desconfiança e o ódio, antes a salvo nas relações de parentesco ou de amizade, destituem o laço afetivo de pessoas que antes se relacionavam como comunidade política, à distância do poder ou do desejo de dominação. Como escreveu La Boétie no século XVI, a amizade é essa relação entre homens livres e iguais, tecida no bem-querer e no bem-fazer, em que os amigos suprem reciprocamente as limitações uns dos outros e formam uma companhia de homens livres que imita a 
autossuficiência do divino e diminui os efeitos dramáticos da condição humana de seres expostos, vulneráveis e mortais. Até mesmo os vínculos da vida privada encontram-se em extinção (MATOS, 2015, p.199-207).

De fato, a violência autoprovocada envolve questões complexas com fatores condicionantes variados que influenciam, de forma direta e indireta, na violência e na saúde mental dos indivíduos, tratando-se, também, de um problema de saúde pública. Com tudo, os profissionais que atuam nos estabelecimentos de ensino devem estar informados e treinados para lidar com essa questão, e diante disso, realizamos 0 seguinte questionamento: Apesar de se trata de um problema de saúde pública, como os estabelecimentos de ensino públicas e privados deverão atuar na prevenção da violência autoprovocada diante de tantos fatores condicionantes?

\section{PROCEDIMENTO DE NOTIFICAÇÃO COMPULSÓRIA NOS ESTABELECIMENTOS DE ENSINO}

A saúde trata-se de Direito de todos, pois, consagrado no artigo $6^{\circ}$ da Constituição Federal de 1988, é no artigo 196 e seguintes que o direito à saúde encontrou sua maior concretização ao nível normativo-constitucional, para além de uma significativa e abrangente regulamentação normativa na esfera infraconstitucional, com destaque para as leis que dispõe sobre a organização e benefícios do Sistema Único de Saúde - SUS. Ao se realizar uma leitura dos artigos 196 a 200, o direito à saúde como direito subjetivo, de todos, portanto de titularidade universal (SARLET, et al., 2012, p.577).

Além de estabelecer o acesso universal e igualitário às ações e prestações nesta esfera, impôs aos poderes públicos uma série de tarefas nesta seara, como a de promover políticas sociais e econômicas que visem à redução do risco de doença e de outros agravos (SARLET, et al., 2012, p.577).

A saúde, também, pode ser entendido como sendo um direito fundamental do ser humano, devendo o Estado prover as condições indispensáveis ao seu pleno exercício através da formulação e execução de políticas econômicas e sociais que visem à redução de riscos de doenças e de outros agravos e no estabelecimento de 
condições que assegurem acesso universal e igualitário às ações e aos serviços para a sua promoção, proteção e recuperação (BRASIL, 1990).

O recurso às normas programáticas visa reconciliar o Estado e a Sociedade (BONAVIDES, 2004, p.236). Para José Joaquim Gomes Canotilho (1993, p.184), o sentido destas normas não é, porém, o assinalado pela doutrina tradicional como simples programas, exortações morais, declarações, sentenças políticas, aforismos políticos, promessas, apelos ao legislador ou programas futuros, são juridicamente desprovidos de qualquer vinculo. Às normas programáticas é reconhecido um valor jurídico constitucionalmente idêntico ao dos restantes preceitos da constituição. Não deve, pois, falar-se de simples eficácia programática (ou diretiva), porque qualquer norma constitucional deve considerar-se obrigatória perante quaisquer órgãos do poder político.

Segundo Canotilho (1993, p.184), concretizando melhor, a positividade jurídico-constitucional das normas programáticas significa fundamentalmente:

\begin{abstract}
1. Vinculação do legislador, de forma permanente, à sua realização (imposição constitucional); 2. Vinculação positiva de todos os órgãos concretizadores, devendo estes tomá-las em consideração como diretivas materiais permanentes, em qualquer dos momentos da atividade concretizadora (legislação, execução, jurisdição); 3 . Vinculação, na qualidade de limites materiais negativos, dos poderes públicos, justificando a eventual censura, sob a forma de inconstitucionalidade, em relação aos atos que as contrariam.
\end{abstract}

Dessa forma, as normas programáticas cingem-se a enunciar as linhas diretoras que devem ser perseguidas pelos Poderes Públicos, como saúde, educação, lazer, moradia etc. Elas comandam o seu próprio procedimento legislativo, consagrando programas constitucionais a serem cumpridos mediante legislação integrativa da manifestação constituinte. As normas programáticas não contemplam interesses ou direitos regulados em $\mathrm{si}$, mas, apenas, metas ou escopos a serem seguidos pelo Legislativo, Executivo e Judiciário. Buscam a consecução dos fins sociais pelo Estado, motivo por que desempenham função eficacial de programa (BULOS, 2014, p.484).

Visando garantir a proteção da saúde da criança e do adolescente, bem como efetivar políticas sociais públicas, bem como prevê o artigo $7^{\circ}$ do Estatuto da Criança 
e do Adolescente, no dia 26 de abril de 2019, foi sancionada a Lei número 13.819/2019 (BRASIL, 2019d) que institui a Política Nacional de Prevenção da Automutilação e do Suicídio, a ser implementada pela União, pelos Estados, pelos Municípios, Distrito Federal, com a participação da sociedade civil ${ }^{2}$ e de instituições privadas. (artigo 1 e parágrafo único do artigo 2º).

Na prestação da saúde, esta desempenha papel importantíssimo o Sistema Único a que se refere o artigo 198 da Constituição Federal. Ele consiste numa integração das ações e serviços públicos de saúde, tendo por diretrizes o princípio da descentralização, no nível de cada esfera de governo, o atendimento integral e a participação da comunidade (BRASIL; et al., 2017).

Como de praxe, para a realização desse trabalho o legislador atribuiu a responsabilização para a efetivação dessa política à todos os entes federados, para que, de forma mútua e em regime de colaboração, possam alcançar os objetivos que essa nova Lei se propõem: a prevenção da automutilação e do suicídio em todo o território nacional.

A efetivação de eventuais ações depende de condições estruturais dos diferentes trabalhos e espaços interinstitucionais, das equipes multidisciplinares, que não devem atuar independentemente, mas movidas pela conjugação de vários saberes e práticas aplicadas, considerando ser uma realidade complexa. ${ }^{3}$

Ao realizar a leitura da Lei 13.819/19, somente nos incisos do artigo 6으, parágrafo $1^{\circ}$ é que se ponta quais são as modalidades de violência autoprovocada, sendo elas o suicídio consumado, a tentativa de suicídio e o ato de automutilação, com ou sem ideação suicida.

O artigo 3ํㅡㄹ traça os objetivos dessa política, sendo eles (BRASIL, 2019d):

São objetivos da Política Nacional de Prevenção da Automutilação e do Suicídio: I - promover a saúde mental; II - prevenir a violência

\footnotetext{
${ }^{2}$ Vera Maria Vidal Peroni elabora uma crítica, quando questiona o que significam democracia e participação, para a teoria da Terceira Via, quando a sociedade civil é muito mais chamada a executar tarefas do que a participar nas decisões e no controle social. A democratização seria apenas para repassar tarefas que deveriam ser do Estado. A sociedade acaba se responsabilizando pela execução das políticas sociais em nome da democracia. (PERONI, 2012. p. 22).

${ }^{3}$ BRASIL, 2017; 51 :e 03276 apud Morin E. Introdução ao pensamento complexo. 4⿳亠丷a ed. Porto Alegre: Sulina; 2011.; Morin E, Almeida MC, Carvalho EA. Educação e complexidade: os sete saberes e outros ensaios. 6 ${ }^{a}$ ed. São Paulo: Cortez; 2013. Disponível em: http://www.scielo.br/pdf/reeusp/v51/1980220X-reeusp-S1980-220X2016039303276. pdf. Acesso em: 25/05/2016. p. 7.
} 


\begin{abstract}
autoprovocada; III - controlar os fatores determinantes e condicionantes da saúde mental; IV - garantir o acesso à atenção psicossocial das pessoas em sofrimento psíquico agudo ou crônico, especialmente daquelas com histórico de ideação suicida, automutilações e tentativa de suicídio; V - abordar adequadamente os familiares e as pessoas próximas das vítimas de suicídio e garantir-lhes assistência psicossocial; VI - informar e sensibilizar a sociedade sobre a importância e a relevância das lesões autoprovocadas como problemas de saúde pública passíveis de prevenção; VII - promover a articulação intersetorial para a prevenção do suicídio, envolvendo entidades de saúde, educação, comunicação, imprensa, polícia, entre outras; VIII promover a notificação de eventos, o desenvolvimento e o aprimoramento de métodos de coleta e análise de dados sobre automutilações, tentativas de suicídio e suicídios consumados, envolvendo a União, os Estados, o Distrito Federal, os Municípios e os estabelecimentos de saúde e de medicina legal, para subsidiar a formulação de políticas e tomadas de decisão; IX - promover a educação permanente de gestores e de profissionais de saúde em todos os níveis de atenção quanto ao sofrimento psíquico e às lesões autoprovocadas. (grifos nosso)
\end{abstract}

Notasse nesse dispositivo a evidente preocupação do legislador em "promover", "prevenir", "controlar" e "informar" sobre a automutilação e o suicídio. A prevenção é o principal objetivo nas ações realizadas pela saúde pública e, também, da nova Lei, articulando um trabalho intersetorial e envolvendo entidades da saúde, educação, comunicação, imprensa, polícia, entre outras.

Para tanto, para combater e prevenir um problema se faz necessário entendêlo, ou seja, "como ocorre?", "onde ocorre?", conhecer e aprofundar a análise dos fatores condicionantes que motivam as causas da violência autoprovocada, bem como a obtenção e coleta de dados.

Nos estudos realizados por Howlett e Ramesh (2013, p.124), estes enfatizam a importância da coleta de dados e informações sobre determinado tema. Ao se analisar as fases de formulação de política pública, mais especificamente na fase de apreciação, se identificam e se consideram os dados e as evidências. Essas podem tomar a forma de relatórios de pesquisa, depoimento de experts, informações das partes interessadas, ou consulta pública sobre problemas que tenham sido identificados. Aqui o governo tanto gera quanto recebe informações sobre os problemas e suas soluções objetivando uma posterior tomada de decisão.

Contemporaneamente, os trabalhos de coleta de dados têm sido uma ferramenta importante e fundamental para se conhecer um determinado problema e elaborar hipóteses de soluções, e isso fica muito evidente na leitura do artigo $3^{\circ}$, inciso VIII. É através do mapeamento e análise de dados que políticas públicas e programas 
poderão ser elaborados e implementadas para que sejam efetivas, eficazes e eficientes.

A construção de um banco de dados para o enfrentamento do problema é estruturado no artigo $6^{\circ}$ da Lei, quando trata da "notificação compulsória" dos casos de violência autoprovocada. Segundo esse dispositivo, os casos suspeitos ou confirmados de violência autoprovocada são de notificação compulsória pelos estabelecimentos de saúde públicos e privados às autoridades sanitárias ${ }^{4}$, estabelecimentos de ensino públicos e privados ao conselho tutelar.

Sob o viés educacional, as escolas são demandadas quanto a obrigação de realizar as notificações, bem como, também demandam a atuação do Conselho Tutelar $^{5}$, que deverá atuar nos casos que envolverem criança ou adolescente, recebendo as notificações tão somente sobre o suicídio consumado (parágrafo $2^{\circ}$ ).

Quanto à forma de prevenção, combate e estudo da violência autoprovocada, a nova Lei propõe, como um "meio", o procedimento de notificação compulsória. Ao se notificar a prática da violência autoprovocada, o Estado terá condições de aprofundar medidas relacionadas às condicionantes dessa modalidade de violência.

A proposta é legitimar o aspecto procedimental da construção do conhecimento e informação sobre o tema. Ocorre que, diante de tantas outras responsabilidades atribuídas aos estabelecimentos de ensino, caberá também a estes obter e transmitir informações e treinamentos para realizar o procedimento de notificação compulsória ao Conselho Tutelar, conforme determina a nova Lei.

A notificação compulsória deverá ocorrer de forma sigilosa e as autoridades que as receberem deverão mantê-las em sigilo (artigo $6^{\circ}$, parágrafo $3^{\circ}$ ). Quanto ao sigilo, o artigo 10 da Lei no 6.259, de 30 de outubro de 1975 versa que a notificação compulsória de casos de doenças tem caráter sigiloso, obrigando, nesse sentido, as autoridades sanitárias que a tenham recebido. Dessa forma, a identificação do paciente de doenças referidas no artigo 10, fora do âmbito médico sanitário, somente poderá efetivar-se, em caráter excepcional, em caso de grande risco à comunidade a

${ }^{4} \mathrm{O}$ Ministério da Saúde define autoridade sanitária como órgãos ou agentes públicos competentes da área da saúde, com atribuição legal no âmbito da vigilância e da atenção à saúde (artigo 4 inciso III). (BRASIL, 2013).

${ }^{5} \mathrm{O}$ Conselho Tutelar possui o status de autoridade pública, investida inclusive do poder de requisição em relação a serviços públicos nas áreas da saúde, educação, serviço social, previdência, trabalho e segurança. (LIBERATI, 2004. p. 303). 
juízo da autoridade sanitária e com conhecimento prévio do paciente ou do seu responsável. (parágrafo único.)

Em 17 de fevereiro de 2016, o Ministério da Saúde emitiu a Portaria $n^{\circ}$ 204/2016 que define a Lista Nacional de Notificação Compulsória de doenças, agravos e eventos de saúde pública nos serviços de saúde públicos e privados em todo o território nacional. No artigo $2^{\circ}$, inciso I desta Portaria, versa que:

Para fins de notificação compulsória de importância nacional, serão considerados os seguintes conceitos: I - agravo: qualquer dano à integridade física ou mental do indivíduo, provocado por circunstâncias nocivas, tais como acidentes, intoxicações por substâncias químicas, abuso de drogas ou lesões decorrentes de violências interpessoais, como agressões e maus tratos, e lesão autoprovocada. (grifo nosso)

Quanto à classificação de notificação compulsória, o artigo 2ํe e seus incisos da Portaria 204 as classificam das seguintes formas:

\begin{abstract}
VI - notificação compulsória: comunicação obrigatória à autoridade de saúde, realizada pelos médicos, profissionais de saúde ou responsáveis pelos estabelecimentos de saúde, públicos ou privados, sobre a ocorrência de suspeita ou confirmação de doença, agravo ou evento de saúde pública, descritos no anexo, podendo ser imediata ou semanal; VII - notificação compulsória imediata $(\mathrm{NCl})$ : notificação compulsória realizada em até 24 (vinte e quatro) horas, a partir do conhecimento da ocorrência de doença, agravo ou evento de saúde pública, pelo meio de comunicação mais rápido disponível; VIII - notificação compulsória semanal (NCS): notificação compulsória realizada em até 7 (sete) dias, a partir do conhecimento da ocorrência de doença ou agravo; IX - notificação compulsória negativa: comunicação semanal realizada pelo responsável pelo estabelecimento de saúde à autoridade de saúde, informando que na semana epidemiológica não foi identificado nenhuma doença, agravo ou evento de saúde pública constante da Lista de Notificação Compulsória; e X - vigilância sentinela: modelo de vigilância realizada a partir de estabelecimento de saúde estratégico para a vigilância de morbidade, mortalidade ou agentes etiológicos de interesse para a saúde pública, com participação facultativa, segundo norma técnica específica estabelecida pela Secretaria de Vigilância em Saúde (SVS/MS).
\end{abstract}

A observação que realizamos sobre 0 artigo $6^{\circ}$, parágrafo $5^{\circ}$ da Lei 13.819/19, é que esse dispositivo trata do treinamento dos profissionais que atuam nas escolas quanto à notificação de casos da violência autoprovocada, e não de seu efetivo combate nas instituições de ensino. 
Isso demonstra que o legislador reconhece a complexidade do problema a ser enfrentado e a necessidade de um tratamento especializado por profissionais da área da saúde. Além disso, na ocorrência de violência autoprovocada, seja ela consumada ou tentada, utilizam-se os itens da Classificação Internacional de Doenças e Problemas Relacionadas à Saúde - CID - 10 de X60 a X84 - Lesões autoprovocadas intencionalmente.

Gilmar Ferreira Mendes (2012, p.903-904) observa que o estudo do direito à saúde no Brasil leva a concluir que os problemas de eficácia social desse direito fundamental devem-se muito mais à questões ligadas à implementação e manutenção das políticas públicas de saúde já existentes, do que à falta de legislação específica. Em outros termos, o problema não é de inexistência, mas de execução (administrativa) das políticas públicas pelos entes federados.

\section{POLÍTICAS DE SAÚDE PÚBLICA E EDUCACIONAIS PARA A PREVENÇÃO DA AUTOMUTILAÇÃO E DO SUICÍDIO.}

A Constituição de 1988 é a primeira Carta brasileira a consagrar o direito fundamental à saúde. Textos constitucionais anteriores possuíam apenas disposições esparsas sobre a questão, como a Constituição de 1824, que fazia referência à garantia de "socorros públicos" (art. 179, XXXI). (MENDES, 2012, p.901).

O direito à saúde, direito público subjetivo é assegurado mediante políticas sociais e econômicas, ou seja, não há um direito absoluto a todo e qualquer procedimento necessário para a proteção, promoção e recuperação da saúde, independentemente da existência de uma política pública que o concretize. Há um direito público subjetivo a políticas públicas que promovam, protejam e recuperem a saúde (MENDES, 2012, p.901).

A garantia mediante políticas sociais e econômicas ressalva, justamente, a necessidade de formulação de políticas públicas que concretizem o direito à saúde por meio de escolhas alocativas. É incontestável que, além da necessidade de se distribuir recursos naturalmente escassos por meio de critérios distributivos, a própria evolução da medicina impõe um viés programático ao direito à saúde, pois sempre 
haverá uma nova descoberta, um novo exame, um novo prognóstico ou procedimento cirúrgico, uma nova doença ou a volta de uma doença supostamente erradicada, (MENDES, 2012, p.902) como, por exemplo, a violência autoprovocada.

Tais políticas visam à redução do risco de doença e outros agravos, de forma a evidenciar sua dimensão preventiva. As ações preventivas na área da saúde foram, inclusive, indicadas como prioritárias pelo artigo 198, inciso II, da Constituição (MENDES, 2012, p.902).

Em uma visão geral, o direito à saúde há de se efetivar mediante ações específicas (dimensão individual) e mediante amplas políticas públicas que visem à redução do risco de doença e de outros agravos (dimensão coletiva). Nessas perspectivas, as pretensões formuladas e formuláveis tanto poderão dizer respeito a atos concretos como a políticas e ações administrativas que contribuam para a melhoria do sistema de saúde, incluídas aqui as normas de organização e procedimento (MENDES, 2012, p.905).

Para Maria Paula Dallari Bucci (2006, p.65), as políticas públicas explicitadas pelo artigo 196 da Constituição Federal, constituem a garantia do direito social à saúde, definindo a norma constitucional os objetivos de tais políticas, isto é, o objetivo final e amplo de garantia do direito de todos à saúde é de ser atingido pelo objetivo específico de redução de riscos e de observância dos princípios de universalidade e igualdade no acesso às ações e serviços de proteção, promoção e recuperação da saúde.

Enxergar o direito como objetivo de iniciativa de desenvolvimento sugere, em primeiro lugar, que se reconheça que o arcabouço jurídico tenha a característica de formalizar metas e indicar os "pontos de chegada" de tais políticas. O direito, nesse sentido, pode ser entendido como uma diretriz normativa (prescritiva) que delimita, ainda que de forma geral e sem determinação prévia de meios, o que deve ser perseguido em termos de ação governamental. Ele é, nessa acepção, uma bússola cujo norte são os objetivos dados politicamente, de acordo com os limites de uma ordem jurídica. Um exemplo disso seria o artigo 196 da Constituição Federal (COUTINHO, 2013, p.99).

A promoção da saúde é o nome dado ao processo de capacitação da comunidade para atuar na melhoria de sua qualidade de vida e saúde, incluindo uma 
maior participação no controle deste processo. Para atingir um estado de completo bem-estar físico, mental e social os indivíduos e grupos devem saber identificar aspirações, satisfazer necessidades e modificar favoravelmente o meio ambiente. A saúde deve ser vista como um recurso para a vida, e não como objetivo de viver. Nesse sentido, a saúde é um conceito positivo, que enfatiza os recursos sociais e pessoais, bem como as capacidades físicas. Assim, a promoção da saúde não é responsabilidade exclusiva do setor saúde, e vai para além de um estilo de vida saudável, na direção de um bem-estar global (CARTA DE OTAWA ,1986, p.1).

Para evitar o suicídio a Organização Mundial da Saúde - OMS (KRUG, 2002, p.197) propõe soluções como o tratamento de transtorno mentais. Há evidências de que instruir os profissionais responsáveis por cuidados médicos para diagnosticarem e tratarem pessoas com transtornos emocionais pode ser uma maneira eficiente de reduzirem-se os índices de suicídio entre as pessoas de risco. Outra solução de tratamento proposta pela OMS é a farmacoterapia, pela sua eficácia nos processos neurobiológicos que são associados a determinadas condições psiquiátricas, inclusive as que se relacionam ao comportamento suicida. Nas intervenções comportamentais, um profissional da área de saúde mental conduz sessões de terapia com o paciente, discutindo o comportamento suicida anterior, o atual e também os pensamentos suicidas.

Em 1999, a Organização Mundial de Saúde (KRUG, 2002, p.202) lançou uma iniciativa global para a prevenção do suicídio com os seguintes objetivos:

- Obter uma redução duradoura na frequência dos comportamentos suicidas com ênfase em países emergentes e em países em transição social e econômica;

- Identificar, avaliar e eliminar no estágio inicial, o máximo possível, fatores que possam levar jovens a cometer o suicídio;

- Aumentar a conscientização geral sobre o suicídio e fornecer apoio psicossocial às pessoas com pensamentos suicidas ou que já tentaram o suicídio, bem como, aos amigos e parentes dos que tentaram ou realizaram o suicídio. 
A principal estratégia para a implementação dessa iniciativa global segue dois direcionamentos básicos associados às linhas de ação da estratégia cuidados básicos com a saúde da Organização Mundial de Saúde (KRUG, 2002, p.202):

- $\quad$ Organização de atividades multissetoriais regionais, nacionais e globais para aumentar a conscientização sobre o comportamento suicida e como efetivamente evitá-lo;

- Fortalecimento dos recursos dos países para desenvolver e avaliar políticas e programas nacionais para a prevenção do suicídio, que podem incluir o apoio e tratamento das populações em risco, como pessoas com depressão, idosos e jovens; redução da disponibilidade de meios para se cometer o suicídio, como, por exemplo, as substâncias tóxicas, e do acesso a eles; o apoio e reforço às entidades dedicadas aos sobreviventes do suicídio; treinamento de profissionais da área de assistência básica à saúde e de outros setores relevantes.

Os esforços de prevenção do suicídio serão ineficazes se não forem estabelecidos dentro de uma estrutura que englobe planejamento em larga escala desenvolvido por equipes multidisciplinares que envolvam representantes governamentais, planejadores e profissionais da área de saúde pública, e pesquisadores e profissionais de diferentes disciplinas e setores. Grandes investimentos em planejamento, recursos e colaboração entre esses grupos precisam ser empreendidos a fim de se minimizar este importante problema de saúde pública (KRUG, 2002, p.202).

A prevenção do suicídio não se limita à rede de saúde, mas deve ir além dela, sendo necessária a existência de medidas em diversos âmbitos na sociedade, que poderão colaborar para diminuição das taxas de suicídio. A prevenção do suicídio deve ser também um movimento que leva em consideração o biológico, psicológico, político, social e cultural, no qual o indivíduo é considerado como um todo em sua complexidade (ABP, 2014, p.50).

A promoção de qualidade de vida, por sua vez, incentiva espaços de promoção de saúde na comunidade, como a realização de grupos de autoajuda nas igrejas, escolas, associações e ONGs. Controla e regula o acesso aos métodos mais utilizados para prática de suicídio, como venenos e a restrição às armas de fogo, 
realiza construções inteligentes e planejamento da cidade com medidas de segurança, comprometimento dos órgãos responsáveis e campanhas para construções que atendam a essas medidas de segurança (ABP, 2014, p.50-51).

Visando atender os objetivos propostos pela OMS, bem como colocar em prática suas estratégias, o Brasil elaborou a Política Nacional de Saúde Mental. Tratase de uma ação do Governo Federal, coordenada pelo Ministério da Saúde, que compreende as estratégias e diretrizes adotadas pelo país para organizar a assistência às pessoas com necessidades de tratamento e cuidados específicos em saúde mental. Abrange a atenção a pessoas com necessidades relacionadas a transtornos mentais como depressão, ansiedade, esquizofrenia, transtorno afetivo bipolar, transtorno obsessivo-compulsivo etc., e pessoas com quadro de uso nocivo e dependência de substâncias psicoativas, como álcool, cocaína, crack e outras drogas (BRASIL, 2019b).

Nesse contexto, o Centro de Valorização da Vida - CVV, fundado no Estado de São Paulo no ano de 1962, associação civil filantrópica, sem fins lucrativos, assumiu como tarefa, desde a sua criação, estimular essa discussão. O CVV reúne diversos textos, estudos e discussões a respeito da violência autoprovocada, além de demandar por colaboradores, pesquisadores, profissionais da saúde, educadores, pessoas impactadas diretamente pelo problema ou, simplesmente, um interessado pela vida humana (CVV)

O Centro ainda realiza apoio emocional e prevenção do suicídio, atendendo voluntária e gratuitamente todas as pessoas que querem e precisam conversar, sob total sigilo, por telefone, e-mail, chat e VOIP 24 horas todos os dias. A ligação para o CVV em parceria com o SUS, por meio do número 188, são gratuitas a partir de qualquer linha telefônica fixa ou celular (BRASIL, 2019c).

O CVV segue a orientação da OMS (KRUG, 2002, p.199) quanto à criação de serviços comunitários voltados para a saúde mental. Um centro de prevenção do suicídio destinasse a servir como um centro de atendimento a crises, oferecendo ajuda imediata, geralmente por telefone, convergindo com o previsto no artigo $4^{\circ} \mathrm{da}$ Lei 13.819/19, mas existem também programas de aconselhamento face-a-face e um tipo de trabalho que vai até o paciente. 
Outra ação elaborada pelo Ministério da Saúde é o "Setembro Amarelo", mês de prevenção do suicídio no qual o Ministério da Saúde apresenta a Agenda de Ações Estratégicas para a promoção da saúde, vigilância e prevenção do suicídio no Brasil, que estabelece um rol de ações relacionadas à qualificação da vigilância e ao fortalecimento das ações de promoção da saúde, prevenção do suicídio e atenção às vítimas de tentativas e suicídio e seus familiares (BRASIL, 2017ª̣ , p.7).

Desde 2006, com a publicação da Portaria no 1.876, de 14 de agosto de 2006 que instituiu as Diretrizes Nacionais para a Prevenção do Suicídio, o Ministério da Saúde vem desenvolvendo ações neste campo. Com a publicação desta Agenda de Ações Estratégicas, o Ministério da Saúde ratifica este compromisso, estabelecendo novas ações e responsabilidades para as secretarias, departamentos e coordenações que compõem essa estrutura organizacional (BRASIL, 2017ª , p.7).

A Agenda de Ações Estratégicas para a vigilância e prevenção do suicídio e promoção da saúde no Brasil 2017-2020 objetiva a ampliação do Acordo de Cooperação Técnica com o Centro de Valorização da Vida, além de divulgar materiais direcionados aos profissionais de saúde, população e jornalistas, e organizar discussão permanente de grupo de trabalho envolvendo as secretarias de vigilância, de atenção à saúde e de saúde indígena (BRASIL, 2017ª̣ , p.7).

Até o ano de 2020 a ação "Setembro Amarelo" objetiva ampliar e fortalecer as ações de promoção da saúde, vigilância, prevenção e atenção integral relacionados ao suicídio, para a redução de tentativas e mortes por suicídio por meio da construção do Plano Nacional de Prevenção do Suicídio. A Agenda de Ações Estratégicas e melhoria de notificações, ampliação e qualificação da assistência é composta por 3 eixos (BRASIL, 2017a, p.13-20).

No eixo I há a vigilância e informação, ou seja, qualificação da notificação de tentativa de suicídio, do registro de óbitos, estudos/pesquisas e disseminação de informações. Dessa forma, há a publicação do Boletim Epidemiológico, com dados e avaliação sobre tentativa de suicídios e registro de óbitos, que passa a ser anual e disponível no site do Ministério da Saúde, além da apresentação de proposta do grupo de trabalho que é trazer recortes por população.

No eixo II há a prevenção do suicídio e a promoção da saúde da comunicação social e articulação inter e intrasetorial de ações de promoção de saúde. Trata-se de 
um documento inédito para orientar jornalistas. Objetiva-se aqui tratar do "Efeito Contágio" ou "Efeito Werther", pois a forma como o suicídio é divulgado pode, também, levar ou inspirar a outros casos. Dessa forma, evitasse noticiar em primeira página, publicar fotos, palavra suicídio no título, divulgar o método utilizado, o lugar, bilhetes suicidas, apresentar causas únicas, não falar em tentativa "bem-sucedida" ou em "êxito". Em contra partida, deve-se sempre informar telefones úteis, onde buscar ajuda, os sinais de alerta, utilizar linguagem adequada "morto por suicídio" ou "suicídio".

A preocupação em repassar informações para a população, profissionais de saúde e gestores, também ocupa lugar no eixo II, através da distribuição de materiais com foco na identificação de sinais de Alerta: "O que fazer" e "o que não fazer" diante de uma pessoa com risco de suicídio e onde obter ajuda. Para os profissionais da saúde e gestores, há a distribuição de materiais com foco na importância da notificação compulsória da tentativa de suicídio em até $24 \mathrm{~h}$, informações técnicas sobre acolhimento, encaminhamento responsável e articulação de rede (BRASIL, 2017a, p.11-12).

No Eixo III há a gestão e cuidado, ou seja, há a pactuação de fluxos para os serviços de saúde locais com vistas à prevenção do suicídio e integralidade do cuidado e a educação permanente para qualificação das práticas dos profissionais de saúde na prevenção do suicídio.

Os objetivos específicos da Agenda (BRASIL, 2017a, p.11-12) são:

1) Sensibilizar e mobilizar o campo da saúde e demais setores governamentais (educação, justiça, assistência social, cultura, trabalho e emprego, previdência, agricultura e outros) das gestões federal, estadual e municipal, bem como a sociedade civil, para atuar sobre os determinantes sociais relacionados ao fenômeno do suicídio, especialmente os socioeconômicos, ambientais, de trabalho e ocupação, étnico-raciais, de gênero, identidade de gênero e orientação sexual, e outros; 2) Instituir, no âmbito do Ministério da Saúde, o Comitê Gestor de Trabalho de Prevenção do Suicídio no Brasil para elaboração e operacionalização do Plano Nacional de Prevenção do Suicídio, a partir desta Agenda de Ações Estratégicas; 3)Formular e implementar o Plano Nacional de Prevenção do Suicídio no Brasil em parceria com as Secretarias Estaduais e Municipais de Saúde e outros Ministérios, estabelecendo metas, prazos e responsabilidades; 4) Fortalecer a Vigilância de tentativas de suicídio e suicídios completados nas três esferas de gestão, aperfeiçoando os sistemas de informação para qualificar a análise e disseminação de informações de forma completa, adequada e em tempo oportuno, para subsidiar a formulação 


\begin{abstract}
de políticas e tomadas de decisão; 5) Fortalecer a articulação entre Vigilância e Atenção à Saúde, promovendo a utilização efetiva e oportuna dos dados provenientes dos sistemas de informação para subsidiar os serviços de saúde com vistas a garantir maior integralidade, resolutividade e continuidade do cuidado; 6) Fomentar e apoiar os arranjos intersetoriais nos níveis municipal e estadual, que envolvam as áreas de saúde, assistência social, educação, justiça e trabalho, incluindo a sociedade civil nas ações de cuidado e prevenção do suicídio; 7) Incluir a pauta da prevenção do suicídio em Comitês e Grupos Condutores das Redes de Atenção à Saúde existentes ou instituir comitês de prevenção do suicídio locais para monitoramento e avaliação das ações estabelecidas; 8) Ampliar e fortalecer estratégias de educação permanente para sensibilizar e capacitar gestores e profissionais de saúde para a vigilância, qualificação do cuidado e prevenção do suicídio; 9) Fortalecer ações de Comunicação em Saúde para sensibilizar a população em relação ao suicídio e qualificar profissionais de mídia para a disseminação responsável de informações sobre o tema; 10) Reconhecer as especificidades do suicídio entre os povos indígenas no planejamento e implementação de ações estratégicas relacionadas à temática; e 11) Ampliar de forma articulada com os diferentes pontos de atenção em saúde e demais serviços intersetoriais o acesso à atenção psicossocial da população em geral, das pessoas com tentativa de suicídio, familiares e pessoas próximas de vítimas de suicídio. (grifos nosso)
\end{abstract}

Observa-se que grande parte das ações realizados pelo Ministério da Saúde é voltado para o público em geral, não realizando um trabalho específico nos estabelecimentos de ensino públicos e privados.

Sob o viés educacional, a OMS (KRUG, 2002, p.199) orienta o desenvolvimento de programas para montar e treinar profissionais que atuam nas escolas, membros da comunidade e funcionários da área de saúde para identificar pessoas que apresentam riscos de suicídio e encaminhá-las aos serviços de saúde mental. A extensão do treinamento varia de um programa a outro, mas em todos os casos é essencial haver um elo forte com os serviços locais de saúde mental.

No Estatuto da Criança e do Adolescente, o destaque à saúde está presente no Título II, que trata dos direitos fundamentais, sendo o Capítulo I referente ao direito à vida e à saúde, cujo artigo $7^{\circ}$ versa que "[...] a criança e o adolescente têm direito a proteção à vida e à saúde, mediante a efetivação de políticas sociais públicas que permitam o nascimento e o desenvolvimento sadio e harmonioso, em condições dignas de existência" (BRASIL, 1990).

No Brasil, o Programa Saúde na Escola - PSE, instituído por Decreto Presidencial no 6.286, de 5 e dezembro de 2007, resulta do trabalho integrado entre 0 Ministério da Saúde e o Ministério da Educação, na perspectiva de ampliar as ações específicas de saúde aos alunos da rede pública de ensino: ensino fundamental, 
ensino médio, rede federal de educação profissional e tecnológica, educação de jovens e adultos (BRASIL, 2009, p.10).

A escola, que tem como principal incumbência aperfeiçoar processos de ensino-aprendizagem, desempenha, ainda, o papel fundamental na formação e atuação de todos em todas as esferas da vida social. Juntamente com outros espaços sociais, ela efetiva o papel decisivo na formação dos alunos, na compreensão e construção da cidadania e no acesso às políticas públicas. Sendo assim, pode tornarse o local para efetivação da promoção da saúde das crianças, adolescentes e jovens adultos (BRASIL, 2009, p.10).

Nas últimas décadas, a percepção dos países sobre o conceito e a prática de saúde escolar e de promoção da saúde tem mudado. Na década de 80 , a crítica do setor de educação em relação ao setor de saúde de que este não utilizava a escola como uma aliada e parceira tornou-se mais contundente. Ao mesmo tempo, os resultados de vários estudos indicaram que a educação para a saúde, baseada no modelo médico tradicional e focalizada no controle e na prevenção de doenças, é pouco efetiva para estabelecer mudanças de atitudes e opções mais saudáveis de vida que minimizem as situações de risco à saúde de crianças, adolescentes e jovens adultos (BRASIL, 2009, p.10).

Nas escolas, o trabalho de promoção da saúde com os professores, funcionário e estudantes, necessita ter como ponto de partida o que eles sabem e o que eles podem fazer, desenvolvendo em cada um a aptidão de entender o dia-a-dia e agir de forma a agregar comportamentos e atitudes adequados para a melhoria da qualidade de vida. Nesse contexto, as bases são as forças de cada um, no desenvolvimento da autonomia e de competências para o exercício pleno da cidadania. Assim, dos profissionais de saúde e de educação espera-se que, no desempenho das suas funções, assumam uma atitude permanente de empoderamento dos alunos, professores e funcionários das escolas, o princípio básico da promoção da saúde (BRASIL, 2009, p.11).

A escola é um importante espaço para promoção da saúde, principalmente quando forma cidadãos críticos, estimulando a autonomia, o exercício de direitos e deveres, o controle das condições de saúde e qualidade de vida, com opção por atitudes mais saudáveis. As iniciativas de promoção da saúde escolar constituem 
ações efetivas para a conquista de objetivos, o que pode ser potencializado no Brasil pela participação ativa das equipes de Saúde da Família, sempre em associação com as equipes de educação (BRASIL, 2009, p.15).

O Programa Saúde na Escola visa à integração e articulação permanente da educação e da saúde, proporcionando melhoria da qualidade de vida da população brasileira. Tem como objetivo contribuir para uma formação integral de estudantes sobre o tema das ações de promoção, prevenção e atenção à saúde, com vistas ao enfrentamento das vulnerabilidades que afetam o desenvolvimento de crianças e jovens da rede pública de ensino (BRASIL, 2019a) Dessa forma, para fundamentar o contexto de promoção da saúde ao adolescente na escola, optou-se pela teoria da complexidade, que inspira a articulação de saberes em cooperação (BRASIL, 2017b; 51:e 03276 apud MORIN, 2011.; MORIN; ALMEIDA; CARVALHO, 2013, p.2).

O público beneficiário do PSE são formados em educação básica, gestores e profissionais de educação e saúde, comunidade escolar e, de forma mais ampla, estudantes da rede de educação profissional e tecnológica e de educação de jovens e adultos (EJA) (BRASIL, 2019a).

No artigo 4ำ (BRASIL, 2007) do Decreto que institui o PSE são arroladas as ações de saúde previstas no âmbito do PSE e que devem considerar atividades de promoção, prevenção e assistência em saúde, podendo compreender, entre outras a avaliação psicossocial (inciso VII).

Um ponto que chama a atenção, e a OMS ressalta, é que, na medida em que as equipes escolares, como as pedagógicas, se tornam mais preparadas e capacitadas, elas deixam de encaminhar os alunos para os profissionais da área de saúde mental, o que pode, em si, resultar em mais suicídios (KRUG, 2002, p.199 apud LESTER, 1997).

Embora a educação das equipes escolares, familiares e outras pessoas envolvidas com os programas escolares, sejam muito importantes, essas pessoas não conseguem substituir os profissionais da área de saúde mental. Por outro lado, as instalações médicas sozinhas não conseguem atender a todas as necessidades dos jovens, e as escolas devem ser capazes de agir como um mediador para a prevenção do suicídi (KRUG, 2002, p.199 apud LESTER, 1997). 
Um dos objetivos da Programa Saúde nas Escolas é promover a comunicação entre escolas e unidades de saúde, assegurando a troca de informações sobre as condições de saúde dos estudantes. (artigo $2^{\circ}$, inciso VI do Decreto que institui o PSE). A intersetorialidade na implementação do PSE requer a necessária integração e cooperação interprofissional. Este modo de gestão, desenvolvido por meio de processo sistemático de articulação, planejamento e cooperação entre os distintos setores da sociedade e entre as diversas políticas públicas, favorece intervenções nos determinantes sociais (BRASIL, 2017b; 51:e 03276 apud MORIN, 2011.; MORIN; ALMEIDA; CARVALHO, 2013, p.2).

Para ao Conselho Federal de Psicologia (BRASIL, 2013, p.27), a prevenção do comportamento suicida deve começar na família. A família tem de saber lidar com a morte. Geralmente, esse é um assunto que a família esconde, por acreditar que os filhos pequenos não terão recursos psíquicos para encarar a situação. Seguido da família, o trabalho nas escolas é tão importante quanto e deve ser iniciado desde as pré-escolas. Deve-se trabalhar, com as crianças, questões sobre a valorização da vida e as escolas podem organizar programas psicoeducativos que possam mostrar que certos valores precisam ser resgatados. A fraternidade, a harmonia e o respeito são elementos que, quando trabalhados da forma correta, preparam a criança para enfrentar as dificuldades.

É fundamental que se possam fazer trabalhos de treinamento com as equipes de saúde, com as equipes de educação, com engenheiros, arquitetos, com pessoas da área do direito, com bombeiros e policiais, dentre outros profissionais. Se esses profissionais estiverem preparados e souberem identificar qualquer coisa que estiver relacionada ao comportamento suicida, já poderão intervir. E importante, também, frisar que, para se identificarem e intervirem no comportamento suicida, os profissionais devem trabalhar em rede (BRASIL, 2013, p.28).

A teoria da complexidade reitera a importância da integração dos saberes, na constituição de um objeto interdisciplinar, uma vez que permitirá a troca, a cooperação, o diálogo. Neste caso, a necessidade de uma prática que se configura intersetorial para implementação das ações de promoção da saúde aos adolescentes na escola, promovendo o protagonismo destes no cuidado à saúde (BRASIL, 2017b; 51:e 03276 apud MORIN, 2011.; MORIN; ALMEIDA; CARVALHO, 2013, p.2). 


\section{CONCLUSÃO}

Diante da evolução da violência e como ela afeta as diversas searas da vida de um indivíduo, a violência passou a ser classificada como uma questão de saúde pública. Ocorre que, quando há essa aproximação entre violência e saúde, não se pode ignorar que os fatores condicionantes ou determinantes são múltiplos e resultados de uma complexa interação de suas causas. A violência auto provocada também se enquadra como um problema de saúde pública, e à ela também se atribuem diversos fatores condicionantes.

A notificação compulsória trata-se de um procedimento previsto e aplicável na área da saúde pública pela Lei n 6.259/75 e pelo Ministério da Saúde, por meio da Portaria $n^{\circ}$ 204/2016, porém, a Lei 13.819/19 se ocupou em, além de consolidar o procedimento que já é objeto de regulamentação pelo Ministério da Saúde, determina que os estabelecimentos de ensino públicos e privados também o façam. Dessa forma, a interação e o trabalho intersetorial entre a área da saúde pública e educação se faz fundamental.

A efetivação dessas ações depende de condições estruturais dos diferentes trabalhos e espaços interinstitucionais, das equipes multidisciplinares, inclusive nos estabelecimento de ensino, que não devem atuar independentemente, mas movidas pela conjugação de vários saberes e práticas aplicadas, considerando ser uma realidade complexa. A ação intersetorial e multidisciplinar é uma característica inerente ao trabalho de prevenção e combate à violência autoprovocada, não há como realizar políticas e programas sem se demandar ações conjuntas interministeriais.

$\mathrm{Na}$ prática, são poucas as políticas e programas que trabalham com o combate e a prevenção à violência autoprovocada com atuação específica nos estabelecimentos de ensino públicos e privados no Brasil. As políticas e programas que são implementadas atualmente são voltadas à população em geral, ou seja, não há uma atuação específica tendo como público alvo os alunos de estabelecimentos de ensino. 
O programa que mais se aproxima à política instituída pela Lei 13.819/19 é o Programa Saúde na Escola - PSE, que têm, dentre outros objetivos, garantir a avaliação psicossocial do estudante e a troca de informações entre estes, os profissionais que atuam nas escolas com a rede pública de saúde.

Com o advento da nova política instituída pela Lei, corrobora com o fata de que a escola também pode ser um local de combate à violência e a violência autoprovocada, trabalhando de forma coordenada com o setor da saúde, tendo o Programa Saúde na Escola o objetivo de contribuir para a formação dos alunos, informação e treinamento dos funcionários que trabalham nas instituições a cerca do tema, e com vistas ao combate das vulnerabilidades que afetam as crianças e jovens da rede pública e privada de ensino que estão em situação de contínuo e pleno desenvolvimento.

\section{REFERÊNCIAS}

ARENDT, Hannah. Da Violência. Tradução: Maria Claudia Drummond. 1970.

ASSOCIAÇÃO BRASILEIRA DE PSIQUATRIA. - ABP. Suicídio: informando para viver. Conselho Federal de Medicina (CFM). Brasília, 2014. Disponível em: https://www.abp.org.br/cartilha-combate-suicidio. Acesso em: 04/05/2019.

BASTOS, Celso Ribeiro. Curso de direito constitucional [recurso eletrônico]. 20. ed. atual. São Paulo: Saraiva, 1999.

BAUMAN, Zygmunt. Tempos Líquidos. Tradução: Carlos Alberto Medeiros. Rio de Janeiro: Jorgue Zahar. 2007.

BONAVIDES, Paulo. Curso de Direito Constitucional. 15. ed. São Paulo: Malheiros, 2004.

BOURDIEU, Pierre. O poder simbólico. Tradução: Fernando Tomaz. Lisboa: Difel, 1989.

BRASIL, Conselho Federal de Psicologia. O Suicídio e os Desafios para a Psicologia/ Conselho Federal de Psicologia. Brasília: CFP, 2013.

. Ministério da Saúde. Secretaria de Atenção à Saúde. Departamento de Atenção Básica. Saúde na escola. Brasília: Ministério da Saúde, 2009. 
. Ministério da Educação. Programa Saúde na Escola. 2019a. Disponível em: $\quad$ http://portal.mec.gov.br/programa-saude-da-escola/194-secretarias112877938/secad-educacao-continuada-223369541/14578-programa-saude-nasescolas. Acesso em:07/10/2019.

Decreto no 6.286, de 5 de Dezembro de 2007. Disponível em: http://portal. mec.gov.br/index.php?option=com_docman\&view=download\&alias=1726 -saudenaescola-decreto6286-pdf\&category_slug=documentos-pdf\&ltemid=30192. Acesso em:11/05/2019.

- Ministério da Saúde. Brasil. Secretaria de Atenção à Saúde. Departamento de Ações Programáticas Estratégicas. Agenda de Ações Estratégicas para a Vigilância e Prevenção do Suicídio e Promoção da Saúde no Brasil: 2017 a 2020 [recurso eletrônico]. Brasília: Ministério da Saúde, 2017a. Disponível em: http://portalarquivos2.saude.gov.br/images/pdf/2017/setembro/21/17-0522-cartilha--Agenda-Estrategica-publicada.pdf. Acesso em: 11/05/2019.

- Ministério da Saúde. Saúde mental: o que é, doenças, tratamentos e direitos. 2019b. Disponível em: http://portalms.saude.gov.br/saude-de-a-z/saudemental. Acesso em: 18/05/2019.

Centro de Valorização da Vida - CVV. Disponível em: https://www.cvv.org.br/conheca-mais/. Acesso em: 10/05/2019.

. Ministério da Saúde. Prevenção do suicídio: sinais para saber e agir. 2019c. Disponível em: http://portalms.saude.gov.br/saude-de-a-z/suicidio. Acesso em: 10/05/2019.

Disponível

Ministério da Saúde. Portaria $n^{\circ}$ 204, de 17 de fevereiro de 2016.

http://bvsms.saude.gov.br/bvs/saudelegis/gm/2016/prt0204_17_02_2016.html.

em:

Acesso em: 13/05/2019.

Lei $n^{\circ} 6.259$, de 30 de outubro de 1975 . Disponível em: http://www.planalto.gov.br/ccivil_03/leis/l6259.htm. Acesso em: 13/05/2019.

. LEI № 8.069, DE 13 DE JULHO DE 1990. Dispõe sobre o Estatuto da

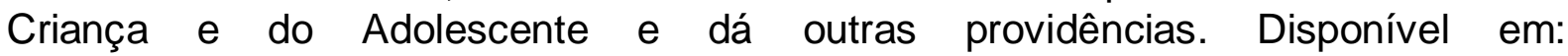
http://www.planalto.gov.br/ccivil_03/leis//8069.htm. Acesso em 25/05/2019.

. Ministério da Saúde. Portaria no 1.139, de 10 de junho de 2013. Disponível em: http://bvsms.saude.gov.br/bvs/saudelegis/gm/2013/prt1139_10_06_2013.html. Acesso em: 14/05/2019.

Constituição da República Federativa do Brasil de 1988. Disponível em: https://www.senado.leg.br/atividade/const/con1988/con1988_14.12.2017/art_200_.a sp. Acesso em: 15/05/2019. 
Lei 13.819 de 26 de Abril de 2019. 2019d Disponível em: http://pesquisa.in.gov.br/imprensa/jsp/visualiza/index.jsp?jornal=515\&pagina=1\&data $=29 / 04 / 2019 \&$ totalArquivos=62. Acesso em: 08/05/2019.

. CID X60 a X84 - Lesões autoprovocadas intencionalmente. Disponível em: http://www.datasus.gov.br/cid10/V2008/WebHelp/x60_x84.htm. Acesso em: 13/05/2019.

Ministério da Saúde. Secretaria de Vigilância em Saúde. Impacto da violência na saúde dos brasileiros / Ministério da Saúde, Secretaria de Vigilância em Saúde. - Brasília: Ministério da Saúde, 2005.

Lei $\mathrm{n}$ - 8.080, de 19 de setembro de 1990. Disponível em: http://www.planalto.gov.br/ccivil_03/leis//8080.htm. Acesso em 15/05/2019.

BRASIL, Eysler Gonçalves Maia; [et. al]. Promoção da saúde de adolescentes e Programa Saúde na Escola: complexidade na articulação saúde e educação in Revista Escola de Enfermagem - USP. 2017b. Disponível em: http://www.scielo.br/pdf/reeusp/v51/1980-220X-reeusp-S1980220X2016039303276.pdf. Acesso em: 25/05/2016.

BUCCI, Maria Paula Dallari. Políticas Públicas: reflexões sobre o conceito jurídico (Org.). São Paulo: Saraiva. 2006.

BULOS, Uadi Lammêgo. Curso de direito constitucional. 8. ed. rev. atual. de acordo com a Emenda Constitucional 76/2013. São Paulo: Saraiva, 2014.

CARTA DE OTAWA. Primeira conferência internacional sobre promoção da saúde Ottawa, novembro de 1986. Disponível em: http://bvsms.saude.gov.br/bvs/publicacoes/carta_ottawa.pdf. Acesso em: 04/05/2019.

CANOTILHO, José Joaquim Gomes. Direito Constitucional. 6. ed. Coimbra: Almedina, 1993.

CALDAS, Ana Lúcia. É preciso falar sobre bullying, depressão e suicídio, alertam especialistas. $2017 . \quad$ Disponível em: http://agenciabrasil.ebc.com.br/geral/noticia/2017-04/e-preciso-falar-sobre-bullyingdepressao-e-suicidio-alertam-especialistas. Acesso em: 13/05/2019.

COUTINHO, Diogo R. Direito, desigualdade e desenvolvimento. São Paulo: Saraiva. 2013.

DURKHEIM. Émile. O suicídio: estudo de psicologia. Tradução: Monica Stahel. São Paulo: Martins Fontes. 2000.

ESTEVENS, João. Os desafios da segurança num mundo global in Scielo. 2016. Disponível em: http://www.scielo.mec.pt/scielo.php?script=sci_arttext\&pid=S164591992016000300010. Acesso em: 13/05/2019. 
FAORO, Raymundo. Os donos do poder: formação do patronato político. 3. ed. rev. Rio de Janeiro: Globo. 2001.

GARRETO, Ana Karla Rabelo. O Desempenho executivo em pacientes que apresentam automutilação. 2015. Dissertação (Mestrado em Ciências) - Faculdade de Medicina de São Paulo, USP, São Paulo, 2015. Disponível em: http://www.teses.usp.br/teses/disponiveis/5/5142/tde-06082015-124601/pt-br.php. Acesso em: 04/05/19.

GIUSTI, Jackeline Suzie. Automutilação: características clínicas e comparação com pacientes com transtorno obsessivo-compulsivo. 2013. Tese (Doutorado em Ciências) - Faculdade de Medicina da Universidade de São Paulo. São Paulo, 2013. Disponível em: <www.teses.usp.br/teses/disponiveis/5/5142/tde- 03102013-113540/pt-br.php>. Acesso em: 04/05/2019.

HALL, Stuart. A identidade cultural na pós-modernidade. Tradução: Tomaz Tadeu da Silva e Guacira Lopes Louro. 10. ed. Rio de Janeiro: DP\&A Editora 1. ed. 1992.

HOWLETT, Michael; RAMESH, Anthony Perl. Política pública: seus ciclos e subsistemas: uma abordagem integradora. Tradução: Francisco G. Heidemann. Rio de Janeiro: Elsevier. 2013.

KRUG E. G. et al., eds. World report on violence and health. Geneva, World Health Organization, 2002.

LIBERATI, Wilson Donizeti (Org.) Direito à educação: uma questão de justiça. São Paulo: Malheiros. 2004.

MARX, Karl H.; ENGELS, Friedrich. Manifesto do Partido Comunista. Recurso Eletrônico. 2. ed. Lisboa: Avante! 1997.

MATOS, Olgária Chain Féres. Antes da chuva: metamorfoses do círculo. Volume 26, número 2. São Paulo: Universidade de São Paulo. 2015. p. 199-207. Disponível em: www.scielo.br/pusp.

MENDES, Gilmar Ferreira; BRANCO, Paulo Gustavo Gonet. Curso de direito constitucional. 7. ed. rev. e atual. - São Paulo: Saraiva, 2012.

MINAYO, Maria Cecília de Souza; SOUZA, Edinilsa Ramos de: Violência e saúde como um campo interdisciplinar e de ação coletiva. História, Ciências, SaúdeManguinhos, IV(3): 513-531, nov. 1997-fev. 1998.

MINAYO, Maria Cecília de Souza. Violência: um problema para a saúde dos brasileiros in BRASIL, Ministério da Saúde. Secretaria de Vigilância em Saúde. Impacto da violência na saúde dos brasileiros / Ministério da Saúde, Secretaria de Vigilância em Saúde. - Brasília: Ministério da Saúde, 2005. 
MINAYO, Maria Cecília de Souza; SOUZA, Edinilsa Ramos de. É possível prevenir a violência? Reflexões a partir do campo da saúde pública in Ciência \& Saúde Coletiva, 4(1):7-32, 1999.

MOTTA, Ivan Dias da. FERREIRA, Fernando Nabão Lopes. Reflexões sobre a personalidade na biopolítica e a ideia de promoção humana. 2017. in IV Congresso internacional de direitos da personalidade e $\mathrm{V}$ Congresso de novos direitos e direitos da personalidade. Centro Universitário de Maringá - UNICESUMAR. Anais.

ORGANIZAÇÃO MUNDIAL DE SAÚDE - OMS. Conceito de saúde segundo a OMS. Disponível em: http://cemi.com.pt/2016/03/04/conceito-de-saude-segundo-oms-who/. Acesso em 06/12/2017.

ORSI, Carlos. Jogo da Baleia Azul: até que ponto devemos nos preocupar? in BBC News Brasil. 2017.2 Disponível em: https://www.bbc.com/portuguese/internacional-39753889. Acesso em: 13/05/2019.

PERINE, Marcelo. Violência e niilismo: o segredo e a tarefa da filosofia in KRITERION, Belo Horizonte, № 106, Dez/2002, (p.108-126).

PERONI, Vera Maria Vidal. A gestão democrática da educação em tempos de parceria entre o público e o privado in Pro-Posições, Campinas, v. 23, n. 2 (68), p. 19-31, maio/ago. 2012.

PILATTI, Carolina de Almeida. Violência e filosofia in Conceitos e formas de violência [recurso eletrônico]: Org. Maura Regina Modena. - Caxias do Sul, RS: Educs, 2016.

RISTUM, Marilene. O conceito de violência de professoras do ensino fundamental. Salvador-Bahia. Tese de Doutorado da Universidade Federa da Bahia. Faculdade de Educação. Programa de Pós-Graduação em Educação. Curso de Doutorado. 2001.

ROSA. Nara Beatriz Kreling da. O uso da Internet como espaço Terapêutico in Cadernos do Aplicação, Porto Alegre, v. 24, n. 2, jul./dez. 2011. Disponível em: https://seer.ufrgs.br/CadernosdoAplicacao/article/view/34795/23005. Acesso em: em 04/05/19.

SARLET, Ingo Wolfgang; MARINONI, Luiz Guilherme; MITIDIERO, Daniel. Curso de direito constitucional. São Paulo: Revista dos Tribunais, 2012.

SEN, Amartya. Identidade e violência: a ilusão do destino. Tradução José Antônio Arantes. 1. ed. São Paulo: lluminuras: Itaú Cultural, 2015.

SOUZA, Jessé. Ralé brasileira: quem é e como vive. Belo Horizonte: Editora UFMG, 2009.

SPOSITO, Marilia Pontes. A instituição escolar e a violência. Instituto de Estudos Avançados da Universidade de São Paulo. Disponível em: 
http://www.iea.usp.br/publicacoes/textos/spositoescolaeviolencia.pdf/at_download/fil e. Acesso em: 07/05/2019.

THESOLIM, Bruna Luiza; [et al]. Suicídios em município do interior de São Paulo: caracterização e prevalência de gêneros in Revista Brasileira Multidisciplinar REBRAM vol. 19, n.1 julho 2016. disponível em: http://www.revistarebram.com/index.php/revistauniara/article/view/372/333. Acesso em: 09/05/2019. 